\title{
HOMINES ET CANES: EL VÍNCULO ENTRE EL SER HUMANO Y EL PERRO EN LA OBRA DE MARCIAL Y JUVENAL
}

Cayetana Paso Rodríguez tana_paso@yahoo.es

\section{RESUMEN}

Utilizando como fuente de estudio los epigramas de Marcial y las sátiras de Juvenal, se considera el vínculo existente entre el hombre y el perro en la Roma de emperador Domiciano, mediante el análisis de los diferentes aspectos de convivencia que el ser humano establecía con este animal. Finalmente, se llega a una reflexión sobre la calidad de vida de estos animales en su coexistencia con el hombre de aquellos días.

Palabras Clave: Marcial, epigrama, Juvenal, sátira, perro, Domiciano, animal.

\section{ABSTRACT}

Based on the epigrams of Martial and the satires of Juvenal, it is considered the relationship between man and dog in Rome under the rule of the Emperor Domitian, through the analysis of the different aspects of the coexistence which human beings maintained with this animal. Resulting in a reflection on the quality of life that these animal had in their coexistence with man in those days.

Key words: Martial, epigram, Juvenal, satire, dog, Domitian, animal. 


\section{INTRODUCCIÓN}

Este artículo es parte de una investigación más amplia acerca de la obra de Marcial y Juvenal ${ }^{1}$. Tiene como finalidad ahondar en el significado que este animal llegó a tener para el ser humano de aquella época. Así, a través del estudio de los textos de los autores mencionados, se han analizado los diferentes aspectos de la vida cotidiana del siglo I en que el hombre coexistía con el perro, intentando sondear la naturaleza de esta relación y el valor que el ser humano le daba.

El vínculo ancestral entre hombres y perros se ha definido a lo largo de la historia de maneras muy diversas. Este animal ha acompañado al ser humano en la labor de la caza y el pastoreo; ha custodiado su casa y sus pertenencias; postrado a sus pies, ha mendigado el sustento y ha compartido su fuego, e incluso su lecho, en un compromiso de calor mutuo. Pero tal vez sea el vínculo de la amistad el que más nos acerque a aquellos hombres de la Roma de Marcial y Juvenal: ese vínculo en el que el animal y el humano renuncian a una parte de sí mismos -de su condición de especie- para ser compañeros de camino.

Los epitafios de animales, que ya aparecían en la literatura griega, fueron también frecuentes en la latina ${ }^{2}$, lo cual de alguna manera sugiere que el hombre romano, al igual que nosotros, buscó algo más que simple compañía y servicio en los animales. Muchos de ellos se retrataron o bien se enterraron con sus animales de compañía -la mayoría, perros y aves-, como algo personalmente amado y cuidado. Hay más de un ejemplo en mosaico de niños jugando alegremente con sus perros o cachorros ${ }^{3}$, así como tumbas de adultos, que a menudo muestran perros sentados o acostados al lado de su amo muerto.

No obstante, el perro es el animal que mejor retrata al ser humano, como si se tratara de un espejo en el que hombre se contempla a sí mismo. Es el compañero por excelencia: hombres y mujeres, ricos y pobres, niños y ancianos, todos han buscado su compañía. En la Roma que retratan Marcial y Juvenal -aquella Roma de Domiciano, de esplendor político y decadencia moral-, la posesión de un perro no era igual que la posesión de un caballo, pues cualquiera podía disponer de uno. Salvo el infortunado Néstor, que, según Marcial, es tan pobre que no tiene «ni un cerrojo, ni una llave ni un perro ni una copa» ${ }^{4}$.

En un epigrama ${ }^{5}$ Marcial advierte: «Aquí no vas a encontrar ni centauros, ni gorgonas, ni harpías: mis páginas tienen sabor a hombre». Y es así cómo su obra y la de Juvenal ofrecen el testimonio de un tiempo en que seres humanos y perros comparten algunas instantáneas. Algunos de esos seres humanos eligieron a los perros como compañeros y amigos, y parece que los quisieron como tal: les dieron de comer de su propio plato, se echaron a dormir junto a ellos para que les dieran calor, lamentaron profundamente su muerte y encomendaron a otros que escribieran bellos epitafios. Otros prefirieron utilizarlos como un mero instrumento para la caza, tanto en espacios abiertos como en

\footnotetext{
${ }^{1}$ Se trata del trabajo de Investigación destinado a obtener el DEA. Ha sido dirigido por la profesora $\mathrm{D}^{\mathrm{a}}$ Carmen Teresa Pabón de Acuña, profesora Titular de Filología Latina en la UNED

2 Catulo (Carmina, 3); Ovidio (Amores, II, 6); Estacio (Silvas, II, 4)

${ }^{3}$ El perro fue muy popular como animal de compañía para niños, como el cachorro del niño pobre que aparece en Juvenal (Sat. IX, 61). No hay que olvidar que en Pompeya el cuerpo de un niño fue descubierto con su perro acostado sobre él, tratando de protegerlo quizás. Asimismo, el perro llegó a convertirse en el arte funerario en un símbolo de fidelidad (Toynbee: 1973, p. 109).

${ }^{4}$ Epigr. XI, 32, 4, trad. de J. Fernández Valverde y A. Ramírez de Verger, 1997.

$5 \mathrm{X}, 4,9 \mathrm{~s}$.
} 
la arena del anfiteatro, o para la vigilancia de sus casas. Y luego están esos otros seres humanos, que aparecerán maltratando a los canes, sacrificándolos y hurgando en sus entrañas, e incluso metiéndolos vivos dentro del cuero de un buey y echándolos al mar junto con otros animales ${ }^{6}$.

\section{Cari CAnes et tristes CANes}

Como en cualquier época, en Roma existieron dos tipos de perros: los afortunados y los míseros. Los primeros son animales con suerte, como las perritas de Zoilo, que pueden saborear las vísceras de un ganso: anserum exta lambentis $^{7}$; o como la perrita Isa, que duerme en la cama junto a su dueño Publio: collo nixa cubat capitque somnos, ut suspiria nulla sentiantur ${ }^{8}$.

Por otro lado, hay perros tan desgraciados como sus amos, al igual que amos tan míseros como sus perros, que se conforman con lo que solo ellos comerían: «huesos» ${ }^{9}$, «trozos de pan duro» ${ }^{10}$, «la porquería de una torta de trigo» ${ }^{11}$ o los desperdicios ${ }^{12}$. Hablar en aquel tiempo de hambre «canina» tiene mucho sentido, pues ya lo dice Marcial: «una nada que conoce cualquier perro» ${ }^{13}$. Esa es la definición del hambre extrema, pues la mayoría de los perros tenían que buscarse la vida y el sustento, y muchos de los que tenían garantizado esto último, se solían alimentar de las sobras y desperdicios que dejaban los humanos con los que compartían espacio. En relación con esto, Marcial describe cómo el glotón Dentón elige a sus amigos según la suntuosidad de su mesa y el tamaño de su cocina. Pero, en opinión del autor, así solo se dejan conquistar los perros ${ }^{14}$. Nosotros sabemos que la suerte es «perra», y parece que Marcial también, pues la buena vida de este «perro» no podrá durar siempre: «Pero pronto, cuando la casa rica te conozca y te abandone, cansada de ti, vendrás a los huesos de la antigua cena» ${ }^{15}$. No es la única vez que Marcial relaciona la glotonería humana con el perro. En el epigrama que Marcial le dedica al avaro Santra, dice que éste «no considera vergonzoso recoger con diestra larga las sobras e incluso lo que los perros dejaron ${ }^{16}$.

Volviendo a las «jerarquías caninas», aún existe otro perro: uno de aspecto faméli$\operatorname{co}^{17}$, con la piel pegada a los huesos ${ }^{18}$, que bebe el agua sucia de las calles en compañía

${ }^{6}$ Según cuenta Juvenal, este era el castigo del parricida, que, tras ser golpeado, era introducido en un saco de cuero cosido (Sat. VIII, 214: culeus) junto a un gallo, un perro, una serpiente y un mono, y de esta manera arrojado al mar («digno de ser botado al mar dentro del cuero de un buey», Sat. XIII, 155, trad. de B. Segura Ramos, 1996). Notemos que Juvenal es la primera fuente que menciona al mono.

7 Marc. Epigr. III, 82, 19.

${ }^{8}$ Epigr. I, 109, 8 s.

${ }^{9}$ Epigr. V, 44, 11: ad ossa.

${ }_{10}$ Epigr. X, 5, 5: caninas panis improbi buccas.

11 Juv. Sat. V, 11: sordes farris canini. Como se puede observar, tanto Marcial como Juvenal utilizan el adjetivo caninus para calificar el pan incomible, digno solo de los canes.

12 Marc. Epigr. VII, 20, 17: analecta quidquid et canes reliquerunt.

${ }^{13}$ Epigr. XII, 48, 6 ss., op. cit.

${ }_{14}$ Epigr. V, 44, 8: maior rapuit canem culina.

15 Epigr. V, 44, 9 ss., op.cit.

16 VII, 20, 16 s., op.cit.

17 Marc. Apoph. 81: tristi... cane; Juv. Sat. VIII, 34 s.: canibus... levibus.

18 Juv. Sat. VIII 34: canibus pigris scabie vetusta levibus. 
de los vagabundos ${ }^{19}$ y deambula de un lado a otro en busca de alimento ${ }^{20}$, incluso por las tenerías de los curtidores ${ }^{21}$ o por los cementerios ${ }^{22}$. Quien mejor describe a este infortunado animal es Juvenal: «A los perros famélicos, pelados por una sarna ancestral, que se ponen a lamer el pico de un candil seco» ${ }^{23}$.

Muchos de los perros que deambulaban por las calles eran los compañeros de los humanos más míseros: los vagabundos. Para explicar la extrema pobreza de Mamuriano, Marcial comenta que este bebe el agua sucia de las calles echado de bruces junto a su perro $^{24}$. Y es que era habitual, y no solo entre los vagabundos, el uso de estos animales para darse calor, como evidencia otra composición de Marcial, dedicada a un morral, en que el poeta menciona la costumbre de los desarrapados cínicos de dormir con sus «famélicos perros» ${ }^{25}$.

\section{HoMines ET CANES}

A continuación se analizará aquellos aspectos de la vida cotidiana en que el hombre romano se valía del perro, con la intención de profundizar en el significado que este animal pudo llegar a tener en aquella época: el perro como compañero de caza (canis venator), como parte de los espectáculos del anfiteatro (canis in harena), como guardián de la casa (cave canem), como animal de compañía (catelli et catellae), como divinidad y como víctima del sacrificio (canis in ara) y como animal necrófago (canes et cadavera).

\section{a. Canis venator}

El perro ha acompañado desde tiempos inmemoriales al hombre durante la caza. La práctica de la cinegética era uno de los pasatiempos más populares entre las clases privilegiadas romanas. Marcial, en uno de sus epigramas, le ofrece su librito a Prisco, su amigo y protector, para que lo lea en su tiempo libre: «Mientras reposan las redes y los molosos ladradores y se aquieta el bosque al no haber ojeado a ningún jabalí» ${ }^{26}$.

La raza canina empleada para la caza dependía principalmente del tipo de presa que se quería cobrar. Marcial, por ejemplo, menciona a la liebre herida por el diente del galgo: gallici canis dente ${ }^{27}$. Esta raza fue representada a menudo en la escultura y, tanto entonces como ahora, sus líneas elegantes fueron muy apreciadas. Para la caza de la liebre también se usaba el lebrel (canis Vertragus o Vertrahus o Veltrahus), muy apreciado

19 Marc. Epigr. I, 92, 10: inmundam... aquam.

20 Epigr. IV, 53, 6: latratos... cibos.

Epigr. VI, 93, 4: detracta cani Transtiberina cutis.

22 Epigr. IX, 29, 12: ne tua non possint eruere ossa canes.

23 Sat. VIII, 34 s., op.cit. Según E. Courtney (1980, p. 390), es muy posible que estos animales, debilitados por la enfermedad, desistieran de ir en busca de agua y se conformaran con el aceite de las lucernas.

${ }^{24}$ Epigr. I, 92, 10: inmundam cum cane pronus aquam.

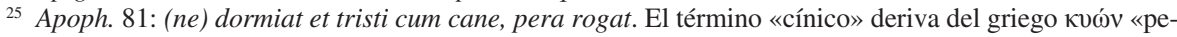
rro». En un epigrama, Marcial describe a un anciano y sucio vagabundo, que pasea con su báculo y su alforja como un falso cínico, pidiéndoles a los viandantes comida a ladridos (Epigr. IV 53, 6: latratos... cibos). El poeta aprovecha y hace un juego de palabras: «Este no es un cínico...; ¿qué es entonces? Un perro» (IV, 53, 8, op.cit.).

${ }^{26}$ XII, 1, 1 s., op.cit.

${ }^{27}$ Epigr. III, 47, 11. 
por su velocidad ${ }^{28}$, al que Marcial califica de acer: «No caza para sí, sino para su amo, el bravo lebrero, que te llevará entre sus dientes la liebre sin dañarla» ${ }^{29}$. El moloso (canis Molossus $)^{30}$, cuya cría los romanos exportaron de Grecia $^{31}$, era empleado como perro guardián, aunque también fue muy estimado como perro de pastoreo y de caza, debido a su corpulencia y fortaleza.

Como es de esperar, muchos de estos perros resultaban heridos o muertos durante las jornadas de cacería, como aquella que describe Marcial en la que «una maloliente zorra $»^{32}$ intenta morder a los animales tras caer en las redes. En relación con esto, el poeta presenta la historia de Lidia, la perra de caza de Dextro, muerta «por el colmillo relampagueante de un furioso jabalí» ${ }^{33}$. Para Dextro, Lidia fue la mejor perra de caza; tanto que pensó que tan valioso animal se merecía un epitafio. Así, Marcial, a modo de aretalogía, describe todas las grandezas del can: es una gran cazadora ${ }^{34}$, que sabe cuándo debe ser agresiva ${ }^{35}$ y cuándo debe ser cariñosa ${ }^{36}$. Y lo sabe porque ha sido adiestrada por los mejores ${ }^{37}$. Además, la fidelidad a su $\mathrm{amo}^{38}$ está por encima de la de legendarios congéneres: por encima de la de Mera, la perra de Erígone ${ }^{39}$; de la de Lélape, el perro de Céfalo $^{40}$. Así que, un animal tan excelente no puede lamentar su propia muerte, que es más noble aún que la de Argos, el perro de Ulises ${ }^{41}$ :

No me ha arrebatado el lento devenir de los días ni la inutilidad de la vejez, tal como fue el destino del perro de Duliquio;

he sido muerta por el colmillo relampagueante de un jabalí furioso, tan grande como lo era el tuyo, Calidón, o el tuyo, Erimanto.

Y no me quejo, a pesar de haber sido arrastrada de golpe bajo las sombras del Infierno. No he podido sucumbir a un destino más glorioso.

(Epigr. XI, 69, 7 ss., op.cit.).

\section{b. Canis in harena}

Los espectáculos de jaurías de perros eran muy habituales en el anfiteatro, y es muy probable que formaran parte de «intermedios» entre combates con bestias de mayor peso y ferocidad. La existencia de este tipo de espectáculos queda patente en el epitafio de la perra Lidia -escrito por Marcial y analizado en el apartado anterior-,

\footnotetext{
${ }^{28}$ Jennison (2005): p. 127. Según Arriano (Cynegetica III, 6), su nombre derivaba de la palabra céltica para «velocidad» (Toynbee: 1973, p. 106).

${ }^{29}$ Apoph. 200, op.cit.

${ }^{30}$ Epigr. XII, 1, 1: latratores Molossi.

${ }^{31}$ Exactamente de Epiro, desde donde fue importado como perro de pastoreo (Jennison: 2005, p. 126; Toynbee: 1973, p. 106).

32 Epigr. X, 37, 14

${ }_{33}$ Epigr. XI, 69, 9: fulmineo spumantis apri sum dente perempta.

34 XI, 69, 2: venatrix.

35 XI, 69, 2: silvis aspera.

${ }_{36} \mathrm{XI}, 69,2$ : blanda domi.

37 XI, 69, 1: amphiteatrales inter nutrita magistros.

38 XI, 69, 3: domino fidissima

39 XI, 69, 4: Erigones... canem.

40 XI, 69, 5: qui... Cephalum... secutus.

${ }^{41} \mathrm{XI}, 69,12$ : fato nobiliore.
} 
que fue entrenada por los adiestradores del anfiteatro ${ }^{42}$, lo cual debía ser habitual en muchos perros de caza.

Marcial, en su De spectaculis liber, describe escenas de cacería en el Coliseo protagonizadas por «veloces molosos» ${ }^{43}$. En una de ellas un gamo intenta escapar de la jauría, demostrando gran habilidad en su huida. El animal termina situándose ante el emperador en actitud suplicante, lo cual parece hacer desistir a sus feroces perseguidores ${ }^{44}$. Marcial convierte así este curioso episodio en una alabanza al César, haciendo una metáfora de su poder y concediéndole a los animales comportamientos y pensamientos humanos: «El César tiene divinidad: sagrado es, sagrado su poder, creedme: las fieras no saben mentir» ${ }^{45}$.

Y no será la única ocasión en que gamos y perros aparezcan juntos en la arena en los versos del poeta de Bílbilis. En un epigrama, ni los perros ni el bestiarius podrán llegar a intervenir debido al ardor con el que los dos gamos se enfrentan el uno contra el otro ${ }^{46}$. En otro, la naturaleza tímida y pacífica de estos animales nada podrá ante su instinto de rivalidad; así que, si el César quiere indultarlos, tendrá que soltar a los perros, pues de este modo los gamos tendrán más oportunidades de vivir ${ }^{47}$.

\section{c. Cave canem}

Sin duda, el testimonio más revelador del papel desempeñado por el perro como guardián de la casa sean los restos hallados en Pompeya, en concreto el de un perro atado a una puerta ${ }^{48}$, al igual que los famosos mosaicos de teselas blancas y negras a la entrada de algunas viviendas (como el de la Casa del poeta trágico, con la célebre inscripción CAVE CANEM).

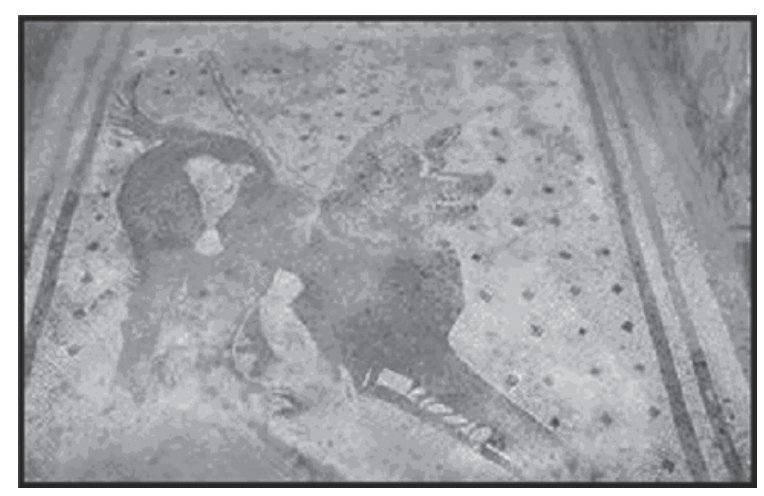

Mosaico de la casa del poeta trágico (Pompeya)

42 XI, 69, 1.

4333 (30, antes 28), 1: veloces... Molossos.

4433 (30, antes 28), 4: praedam non tetigere canes.

4533 (30, antes 28), 7 s., op.cit.

${ }^{46}$ Epigr. IV, 35, 3 s.: spectavere canes praedam stupuitque superbus venator.

${ }^{47}$ IV, 74, 4: Vis, Caesar, dammis parcere? Mitte canes.

${ }^{48}$ Se trata del molde de un perro con su pesado collar, que se muestra retorciéndose en actitud de agonía, seguramente luchando por liberarse de su cadena ante la inminencia de la muerte (Toynbee: 1973, p. 108). 
En Roma era habitual la presencia de perros de guarda en las casas de los ricos: «Aunque se callasen los esclavos, hablarán las mulas y el perro, las jambas de las puertas y los mármoles» ${ }^{49}$. Y es que las casas romanas no estaban construidas a prueba de robos: los muros no eran lo suficientemente sólidos y los tejados permitían fácil acceso a los intrusos a través del impluvium $^{50}$. Son los fuertes ladridos del perro ${ }^{51}$, lo que despierta a una de esas esposas infames que describe Juvenal, la cual inmediatamente pedirá que el animal sea severamente golpeado, junto con su marido ${ }^{52}$.

Pero, como es habitual, tener al animal dentro de la casa tiene sus incovenientes, pues la puede ensuciar con sus excrementos ${ }^{53}$.

\section{d. Catelli et catellae}

En la obra de Marcial, y en menor medida en la de Juvenal, encontramos testimonios de la afición de los romanos por el perro como animal de compañía, sobre todo por los perros pequeños del tipo «maltés» ${ }^{54}$, muy populares durante siglos en Grecia y Egipto.

Tanto en Marcial como Juvenal estos «perritos» y «perritas» suelen aparecer como el delicium de homosexuales y mujeres ${ }^{55}$, retratados de forma caricaturesca y un tanto indigna. Aunque existen casos particulares, como el de la perrita Isa y la pequeña galga en Marcial, que resultan conmovedores ${ }^{56}$.

\section{- Isa, la catella de Publio}

En el elogio a la perrita Isa ${ }^{57}$ algunos estudiosos creen entrever cierta intención de burla o de mera adulación por parte de Marcial respecto al dueño del animal, pues es posible que el epigrama se tratara de un encargo encomendado al poeta ${ }^{58}$. Así, Marcial describe, una por una, todas las virtudes de la singular «perrita»:

Isa es más traviesa que el pájaro de Catulo, Isa es más pura que el beso de una paloma, Isa es más coqueta que cualquier muchacha, Isa es más valiosa que las piedras de India,

49 Juv. Sat. IX, 103 s., op.cit. Como ya comentamos al principio, Marcial describe la pobreza de Néstor, que no tiene casa ni perro que se la guarde: Epigr. XI 32, 4: nec sera, nec clavis nec canis atque calix.

${ }^{50}$ E. Courtney (1980): p. 315 y p. 438.

${ }^{51}$ Sat. VI, 415: latratibus alti.

${ }^{52}$ VI, 416 s.: dominum iubet ante feriri, deinde canem.

53 Juv. Sat. XIV, 64: stercore foeda canino atria.

${ }_{54}$ Eran perros de pelo largo y fino, generalmente blanco, y con el rabo curvado (Jennison: 2005, p. 127).

${ }_{55}$ La excepción es el pasaje de Juvenal en que menciona al catellus de un niño pobre. Este es el único caso en que se habla del perro de un niño, un pequeño que vive en medio del campo: «este niño de campo junto con su madre, las chocejas y el perrito, compañero de juego» (Sat. IX, 61, op.cit.). Juvenal utiliza el término conlusor, «compañero de juego», para el animal.

${ }^{56}$ Como el retrato que el amoroso dueño pide que le hagan a la perrita, con el afán de inmortalizarla. Hay que tener en cuenta que algunas composiciones protagonizadas por animales pueden esconder otras significaciones (entiéndase, eróticas), pues era costumbre entre los romanos nombrar los órganos sexuales (cunnus, mentula) mediante vocablos que designan a animales.

${ }^{57}$ Issa era el equivalente en el lenguaje romano infantil de ipsa, y su significado podría venir a ser «Señorita» (Toynbee: 1973, p. 122)

${ }^{58}$ En la poesía personal latina era habitual el elogio de un animal doméstico de compañía, aunque lo normal era escribirlo cuando este ya había muerto. 
Isa es la perrita, delicia de Publio.

Esta, cuando se queja, pensarás que habla;

puede sentir tristeza y alegría.

Se acuesta apoyada sobre su cuello y coge el sueño

sin que se note suspiro alguno;

y obligada por la necesidad del vientre,

nunca manchó la colcha con gota alguna,

sino que con su pata zalamera le despierta

y le avisa que la baje de la cama y le pide que la suba.

En la casta perrita hay un pudor tan grande

que no conoce a Venus; y no hemos encontrado

a un macho digno de una hembra tan tierna.

Para que la última luz no se la arrebate del todo,

Publio la tiene reproducida en un cuadro,

en el que verás a una Isa tan parecida,

que ni ella misma se parece tanto a sí misma.

Pon para terminar a Isa junto al cuadro:

o creerás que las dos son reales

o creerás que las dos son pintura

(Epigr. I, 109, op.cit).

Es curioso cómo este epigrama tiene una estructura muy similar a uno de los que Marcial dedica a la niña Erotión ${ }^{59}$, en el que también se utiliza la comparación como un recurso de afirmación. Así, podemos decir que la perrita de Publio es traviesa ${ }^{60}$, pura ${ }^{61}$, coqueta $^{62}$ y muy valiosa ${ }^{63}$. Y, además, es tan casta, que no conoce a Venus ${ }^{64}$. Por eso, no pueden encontrar un varón digno de tan tierna muchacha ${ }^{65}$. Como se puede observar, son cualidades humanas las que Marcial atribuye al animal; casi parece que estuviera hablando de una niña (puella). Porque Isa es la delicia de Publio, y él «arde de amor» por ella ${ }^{66}$. $\mathrm{Y}$, por muy pequeña que sea ${ }^{67}$, ella se merece el más grande elogio.

\section{- La catella gallicana}

Ella también es pequeña como Isa ${ }^{68}$. Por eso, Marcial considera que una página entera no es suficiente ${ }^{69}$ para describir sus encantos ${ }^{70}$.

\footnotetext{
${ }^{59} \mathrm{~V}, 37$.

${ }^{60}$ Epigr. I, 109, 1: nequior.

${ }^{61} \mathrm{I}, 109,2$ : purior.

62 I, 109, 3: blandior

${ }^{63}$ I, 109, 4: carior.

${ }^{64}$ I, 109, 14 s.: castae tantus inest pudor catellae, ignorat Venerem.

65 I, 109, 15 s.: nec invenimus dignum tam tenera virum puella.

${ }^{66}$ Epigr. VII, 87, 3: Publius exiguae si flagrat amore catellae.

67 VII, 87, 3: exiguae... catellae.

${ }^{68}$ Apoph. 198: parvae... catellae.

${ }^{69}$ Apoph. 198: brevis est pagina tota.

70 Apoph. 198: delicias.
} 
- Las catellae del homosexual Zoilo

Marcial describe las sucias costumbres del homosexual Zoilo durante la celebración de sus banquetes: «Él, a su vez, girando hacia atrás a la turba de sus pies, entre las perritas que lamen las vísceras de los gansos, distribuye glándulas de jabalí a los gimnastas y obsequia a su concubino con muslos de tórtolas» ${ }^{71}$. Las perritas de Zoilo comparten con los humanos los manjares que caen a los pies de su $\mathrm{amo}^{72}$ deleitándose con su sabroso regalo ${ }^{73}$.

- El catellus de la sucia Maneya

Maneya no tiene una perrita, sino un catellus, que le lame toda la cara, ante lo que Marcial comenta: «no me extraña que al perro le guste comer mierda» ${ }^{74}$.

- La catella de una esposa cruel

En la sátira en que Juvenal criminaliza distintos tipos de mujer, describe la naturaleza perversa de uno de esos tipos de este modo: «Contemplan cómo Alcestis acepta morir por su marido y si se les ofreciese un trueque similar desearían preservar la vida de una perrita a cambio de la muerte de su hombre ${ }^{75}$. Juvenal cree que hay mujeres que harían lo imposible por salvar la vida de sus animales ${ }^{76}$, mientras que, por otro lado, serían capaces de matar a sus maridos.

\section{e. Canis in ara}

La civilización romana consagraba en los altares gran número de animales, de los cuales algunos eran perros. En Roma, durante las Lupercalias, celebradas en el mes de febrero, se sacrificaba un skylax, un cachorro de perro, a Lycus o Lucus, divinidad que representaba al lobo. Una vez sacrificado el animal, tocaban con su cuerpo a todos los asistentes, que de esta manera buscaban la purificación. Por ello llamaron a este rito periskylacismo o «purificación por medio del perro». A este respecto Juvenal comenta el procedimiento adivinatorio de un arúspice armenio ${ }^{77}$, que «hurgará en el pecho de los pollos, en las vísceras de un cachorro de perro, y a veces también en las de un niño» ${ }^{78}$.

Pero los perros en Roma no solo subían al altar como víctimas, sino también como dioses. Juvenal describe una procesión de devotos de Anubis, en que uno de ellos, rodeado de gente vestida de lino y con la cabeza rapada, lleva la máscara de perro y «corre como Anubis y se burla del pueblo doliente» ${ }^{79}$. El perro era en Egipto la representación

71 Epigr. III, 82, 18ss., op.cit.

72 III, 82, 18: ad pedum turbam.

73 III, 82, 19: anserum exta lambentis.

74 Epigr. I, 83, 2, op.cit.

75 VI, 654, op.cit..

76 VI 654: animam servare catellae.

77 Según E. Courtney (1980, p. 333), con «armenio» Juvenal pudo querer decir «persa», pues Armenia se sitúa a medio camino entre Roma y Oriente.

${ }^{78}$ El verbo rimari (Sat. VI, 551 s.: pectora pullorum rimabitur, exta catelli, interdum et pueri) expresa la idea de «abrir las entrañas de la víctima para examinarlas», lo cual está de acuerdo con la práctica romana de la inspección adivinatoria de la vísceras.

79 Sat. VI, 534, op.cit. Es de suponer que Juvenal haga referencia o bien a la mueca de la máscara (que da la impresión de estar riendo) o bien a la actitud del propio sacerdote tras la máscara (que, en opinión del autor, se burlaría de la credulidad de las gentes que asisten a este ritual, en que se llora la muerte de Osiris (Courtney: 1980, p. 331). 
de Anubis, el dios de los muertos, de los embalsamadores y los cementerios, el gran conductor de las almas.

Con todo, a Juvenal le deja sorprendido la costumbre de este pueblo de adorar animales: «allí veneran los gatos, aquí el pez del Río, allí ciudades enteras al perro, nadie a Diana $»^{80}$. Para el poeta de Aquino resulta absurdo que ciudades enteras adoren al perro, pero ninguna se acuerde de Diana, como diosa protectora de estos animales.

\section{f. Canes et cadavera}

La naturaleza necrófaga del perro forma parte de su instinto de cánido, pues otros individuos de esta familia animal, como chacales, zorros y eventualmente lobos, también suelen devorar cadáveres, casi siempre coincidiendo con largas épocas de escasez de alimento.

La presencia de perros en lugares de enterramiento era más que frecuente, pues allí encontraban en ocasiones su único sustento. El epitafio que le dedica Marcial a la vieja Filenis así lo muestra: «Que te sea blanda la tierra y seas cubierta con liviana arena, no vaya a ser que los perros no puedan desenterrar tus huesos ${ }^{81}$. Lo que le desea el poeta a la anciana -que su cuerpo sea devorado por los perros- se lo deseará también a un poeta injurioso al que maldice: «..., que sienta la pelea de los perros y tenga que espantar a las aves carroñeras agitando sus harapos» ${ }^{82}$. Lo que Marcial espera es que, una vez muerto, su enemigo solo pueda sentir la pelea de los perros disputándose su cadáver y las aves de carroña desgarrándole el sudario.

Aunque también era posible que un perro encontrara algo que llevarse a la boca en las tenerías de los curtidores, situadas al otro lado del río Tíber. En un epigrama inspirado en Lucilio ${ }^{83}$, Marcial asegura que Tais huele «peor que la piel arrancada a un perro del otro lado del Tíber» ${ }^{84}$. Con todo, el texto resulta ambiguo, pues no se sabe si la piel se le arranca al propio animal o bien se arrebata de sus fauces ${ }^{85}$.

\section{g. Conclusión}

Veinte siglos nos separan de Marcial y Juvenal y de los seres humanos que aparecen en sus versos, algunos como personas anónimas; otros, con nombres más o menos ficticios; pero todos ellos viviendo con plenitud el papel que les había sido asignado en esa farsa de encuentros y desencuentros que componen la vida diaria del hombre. Este particular desfile de personajes singulares que discurren por los versos de Marcial y Juvenal -y que nada tendrían que envidiar a los «esperpentos» de Valle-Inclán-, componen una instantánea de afectos y desafectos, de bondades y mezquindades; sin duda, un reflejo de nosotros mismos, distorsionado por la herrumbre del paso del tiempo.

\footnotetext{
${ }^{80}$ Sat. XV, 7 s.: oppida tota canem venerantur, nemo Dianam.

${ }^{81}$ Epigr. IX, 29, 12: ne tua non possint eruere ossa canes.

82 Epigr. X, 5, 11: sentiat canum litem abigatque moto noxias aves panno.

83 Ant. Griega XI, 239 y 240.

${ }^{84}$ VI, 93, 4: detracta cani Transtiberina cutis.

${ }^{85}$ El término cutis se diferencia de pellis en cuanto que designa el pellejo, es decir, el cuero del animal, cuando ya se le ha arrancado el pelo.
} 
Hoy en día algunos de los aspectos en los que este animal se pone al servicio del hombre son los mismos de entonces, como el de perro de caza o perro guardián. Sin embargo, actualmente, su utilización en espectáculos públicos es considerada ilegal (peleas de perros) o bien es cuestionada por las continuas denuncias de abuso y maltrato (carreras de perros, circos). Nada que ver con la actitud con la que la Roma antigua promocionaba a costa del erario público las venationes del anfiteatro, en las que intervenían, entre otros animales, los perros.

La calidad de vida de este animal ha mejorado sensiblemente desde aquellos días, aunque entre los perros de caza y de guarda sigan existiendo demasiados casos de maltrato y crueldad. Con todo, en el mundo actual matar perros no está bien visto, sobre todo porque se le han encontrado a este animal nuevas habilidades, como la de perro de servicio (para invidentes, parapléjicos, hemipléjicos, diabéticos, etc.) o la de perro de búsqueda y rescate (en el caso de drogas, explosivos, víctimas humanas). Estas actividades han reforzado la antigua idea de la nobleza y lealtad de este animal para con el ser humano, y tal vez por eso, cada vez más personas lo eligen como compañero y amigo, al igual que lo hicieron los romanos.

Seguramente, a esos extravagantes dueños de perritos que caricaturiza Marcial en sus epigramas se les puede encontrar bastante parecido con muchas personas de hoy en día, y lo interesante es que también entonces eran cuestionados por el «excesivo» cariño con el que cuidaban a sus animales. Los epítetos que Marcial utiliza para Isa, la perrita de Publio, bien podrían ser los de una jovencita o una niña, lo cual denota una tendencia connatural al hombre de cualquier época: la de «humanizar» aquello que ama. Los Publios y los Zoilos actuales aman a sus perritas como lo hicieron aquellos del siglo I, pero, a diferencia de estos, están obligados a cumplir una serie de normas, que, en forma de leyes, los estados modernos han regulado para los animales de compañía. Y es precisamente el cumplimiento o incumplimiento de esas normas lo que convierte a un ser humano en un dueño responsable o irresponsable.

La idea de que la salud y el bienestar del animal de compañía es responsabilidad de su dueño es sin duda un concepto moderno derivado del progreso. Idea de la que nada sabe Juvenal, para el que el perro es un animal más, un elemento adyacente dentro del marco en que el autor critica costumbres, valores y formas de vida. Por eso ni sus perros ni sus seres humanos tienen nombre, pues lo único que le interesa de ellos es que juntos conforman un ejemplo de la decadencia humana.

Punto esencial de nuestra investigación ha sido el análisis del vínculo entre hombres y animales, mediante el cual hemos profundizado en ciertas costumbres y rutinas del ser humano de aquellos días en relación con una especie animal. De este modo, siguiendo el ladrido de los perros, hemos obtenido también información acerca de las personas que los acompañaron: de la pasión por la caza de Dextro; del profundo cariño de Publio por la pequeña Isa; de la ostentación de Zoilo y su gusto por los hermosos muchachos; de la escasa afición por la higiene personal de Maneya y Tais; de la violencia desmesurada de algunas mujeres con sus maridos; de la extrema pobreza de Néstor; de la miseria de Mamuriano o del triste fin de parricidas y crucificados. En fin, todas esas vidas que, que habrían sido anónimas y de las que los epigramas de Marcial y las sátiras de Juvenal han traído noticia hasta nuestros días. 


\section{BIBLIOGRAFÍA}

\section{Ediciones, traducciones y comentarios:}

\section{Marcial:}

Ker, W. (1978-9), Martial. Epigrams I-II. (transl.), London, Harvard University Press.

Fernández Valverde, J. y Ramírez de Verger, A. (1997), Marcial. Epigramas. I-II. (trad. y notas). Madrid, Biblioteca Clásica Gredos.

Fernández Valverde, J. - Montero Cartelle, E. - Moreno Soldevilla, R. (2004), Marco Valerio Marcial. Epigramas. Madrid, Alma Mater, CSIC.

Guillén, J. (2004), Marco Valerio Marcial. Epigramas (texto, intr. y notas de J. Guillén. Revisión de F. Argudo) $2^{\mathrm{a}}$ ed., Zaragoza, Institución Fernando el Católico.

Juvenal:

Courtney, E. (1980), A Commentary on the Satires of Juvenal. London, the Athlone Press, págs. $315,333,390$ y 438.

Segura Ramos, B. (1996), Juvenal. Sátiras (trad.). Madrid, Alma Mater (C.S.I.C.).

Socas, F. (1996), Juvenal. Sátiras (intr., trad. y notas). Madrid, Alianza Editorial.

Villegas Guillén, S. (2002), Décimo Junio Juvenal. Sátiras (pról., trad. y notas). Madrid, Ediciones Clásicas.

\section{Estudios:}

Fortuny Previ, F. (1982), «Consideraciones sobre algunos hapax de Marcial». Anales de la Universidad de Murcia, 40, 111-126.

Highet, G. (1954), Juvenal the Satirist. A study. Oxford University Press, págs 47-160.

Jennison, G. (2005), Animals for Show and Pleasure in Ancient Rome. Pennsylvania University of Pennsylvania Press, págs. 126-127.

PABÓN DE ACuÑA, C. T. (1986): «Manjares y convites en la sátira y el epigrama latinos». Boletín del Museo e Instituto 'Camón Aznar', XV , 27-37.

- (1998): «Marcial y Juan Ramón Jiménez. Coincidencias de sensibilidades». Cuadernos de Filología Clásica. Estudios Latinos, 15 , 283-295.

Sullivan, J. P. (1991), Martial: the unexpected Classic. A literary and historical study. Cambridge Univ. Press, págs. 155-170; 185-206.

Toynbee, J. M. C. (1973), Animals in Roman Life and Art. London, Johns Hopkins University Press, págs. 102-124.

Willis, R. (1993), Mitología. Guía ilustrada de los mitos del mundo. Madrid, Editorial Debate, pág. 42. 